\title{
Spray drift-based pesticide residues on untreated edible crops grown near agricultural areas
}

\author{
Hannah Bolz ${ }^{1,2,3} \cdot$ Christian Sieke $^{1}$ (D) Britta Michalski $^{1} \cdot$ Ralf B. Schäfer $^{2} \cdot$ Roland Kubiak $^{3}$
}

Received: 15 June 2021 / Revised: 15 October 2021 / Accepted: 8 November 2021 / Published online: 17 January 2022

(c) The Author(s) 2022

\begin{abstract}
We aimed to quantify spray drift-based exposure of fruits and vegetables grown in gardens or allotments next to agricultural areas to plant protection products (PPP). The amount of spray drift transported into gardens during the treatment of tall growing crops or field crops was simulated. Two different test systems in an outdoor wind tunnel were used, approximating conditions for the application to both crop types. For the experiments, strawberries, tomatoes and lettuce were used representing non-target food crops in gardens. After spraying, distance-related residues of the tracer pyranine were measured on the three food crops positioned 1-15 m downwind in the non-target area. Additionally, petri dishes were placed in front of the food crops to measure the ground deposition concurrently. For both scenarios, good correlation of residues on the non-target food crops and the ground deposition was found (linear regression model, $\mathrm{R}^{2}=0.88-0.97$ ). But unlike the field crops scenario, the experimental setup of the tall growing crops shows large deviations from the field situation, not allowing the transfer of the results to the field situation. The results of the wind tunnel experiments and of field trials on ground deposition were used to estimate the amount of PPP residues on food crops cultivated near agricultural fields. For example, application of a pesticide ( $1.3 \mathrm{~kg}$ active ingredient per ha ${ }^{-1}$ ) to field crops was estimated to result in residue levels of $0.39 \mathrm{mg} \mathrm{kg}^{-1}$ on lettuce, $0.32 \mathrm{mg} \mathrm{kg}^{-1}$ on strawberries, and $0.06 \mathrm{mg} \mathrm{kg}^{-1}$ on tomatoes cultivated $5 \mathrm{~m}$ from the field, thus indicating an exceedance of the default maximum residue level (MRL) $\left(0.01 \mathrm{mg} \mathrm{kg}^{-1}\right)$. Therefore, further in-depth studies are required to broaden the range of non-target crops and to refine the tall growing crop scenario to allow estimations of spray drift-based residues.
\end{abstract}

Keywords Plant protection products $\cdot$ Spray deposition $\cdot$ Consumer exposure $\cdot$ Basic drift values $\cdot$ Wind tunnel $\cdot$ Pyranine

\section{Introduction}

In Germany, $52 \%$ of the area is agricultural land, about $31 \%$ of the area is covered by forest and $14 \%$ is used for human settlements and transport infrastructure (Umweltbundesamt 2018). The latter contains gardens and allotments (2\%) (Bundesverband Deutscher Gartenfreunde e.V. 2008). Given the high percentage of land use for agriculture, such areas are likely to be in direct vicinity to settlements. This can lead to off-crop exposure when residues of PPP are transported to

Christian Sieke

Christian.sieke@bfr.bund.de

1 German Federal Institute for Risk Assessment, Max-Dohrn-Str. 8-10, 10589 Berlin, Germany

2 Institute for Environmental Sciences, University of Koblenz and Landau, Landau, Germany

3 Institute for AgroEcology, RLP AgroScience GmbH, Neustadt/Weinstr., Germany non-target areas such as gardens, for example via spray drift. The amount of spray drift depends on the physicochemical properties of the PPP, the weather conditions, especially the wind velocity and direction, and the application technique used (Carlsen et al. 2006; Nordby and Skuterud 1975; Nuyttens et al. 2007; De Schampheleire et al. 2009). Spray drift is primarily determined by the droplet size, which in turn depends on the nozzle type, the spray pressure and the presence of adjuvants, among other things (Bird et al. 1996). The smaller the droplets, the higher the amount of spray drift because smaller droplets can travel over longer distances, whereas larger droplets deposit nearby (Bird et al. 1996; Carlsen et al. 2006; Grisso et al. 2019; Hofman 2018). Droplets with a diameter of $0.25 \mathrm{~mm}$ or more can con-tribute to spray drift by wind velocities of $3-4 \mathrm{~m} \mathrm{~s}^{-1}$ but will deposit near the spray boom. Droplets with a diameter of $0.15-0.20 \mathrm{~mm}$ significantly contribute to spray drift and deposit in longer distances. Fine droplets with a diameter below $0.15 \mathrm{~mm}$ can travel up to $20 \mathrm{~m}$ and more at low wind 
velocities (Byass and Lake 1977). Spray drift can be reduced by spraying at low wind speeds, low temperatures, low sun radiation and high humidity, by avoiding small droplets through the addition of additives or the use of spray drift reducing equipment, by the use of low spray pressures or by a reduced spray boom height (Carlsen et al. 2006; Nuyttens et al. 2007).

Many studies have determined the deposition of spray drift on the ground next to agricultural areas, which show that the ground deposition decreases exponentially with distance (Carlsen et al. 2006; Ganzelmeier et al. 1995; Gooijer et al. 2019; Rautmann et al. 2001; Schweizer et al. 2013). In regulatory practice in Germany, basic drift values have been implemented for certain types of crops and development stages describing the amount of spray drift that deposits on the ground relative to the distance from the target area (Bundesamt für Verbraucherschutz und Lebensmittelsicherheit 2020; Ganzelmeier et al. 1995; Rautmann et al. 2001). The basic drift values represent the $90^{\text {th }}$ percentile derived from more than 200 experiments and are expressed as percentage ground deposition of the application rate. The experiments showed that the amount of spray drift from application of PPP to tall growing crops (e.g., orchards, vines and hops) is higher than that from application to field crops (e.g., cereals) due to the different nozzle directions (upwards, sideways and downwards) (Bundesamt für Verbraucherschutz und Lebensmittelsicherheit 2020; Ganzelmeier et al. 1995; Rautmann et al. 2001). For example, based on the basic drift values, approximately $0.6 \%$ and $20 \%$ of the applied amount deposits at a distance of $5 \mathrm{~m}$ to the field during the application of PPP to field crops and orchards, respectively. The highest residue levels were found at a distance of $3 \mathrm{~m}$ to orchards in the early growth stage (29\% of the application rate) (Rautmann et al. 2001). Several other studies showed deposition values comparable to the basic drift values (Carlsen et al. 2006; Dabrowski and Schulz 2003; Gooijer et al. 2019; Schweizer et al. 2013).

While many studies have examined ground deposition and, though less intensively, residue levels in different heights, little is known about the deposition of PPP on edible crops grown adjacent to treated agricultural crops. Some studies examined the deposition and effects of PPP on adjacent vegetation (Boutin et al. 2014; Davis et al. 1994; Marrs et al. 1991; Marrs and Frost 1997; Olszyk et al. 2017; Strandberg et al. 2021). For example, negative effects such as inhibited growth and chlorosis occurred up to $8 \mathrm{~m}$ from an area treated with herbicides (Marrs et al. 1991; Marrs and Frost 1997). Davis et al. (1994) found damaged tomato plants at a distance of $15 \mathrm{~m}$ from the treated area after a herbicide application. Furthermore, seed production and flowering are adversely affected by spray drift (Boutin et al. 2014; Olszyk et al. 2017). Strandberg et al. (2021) found even at a distance of $20 \mathrm{~m}$ adverse effects on the flowering of perennial herbs caused by spray drift of glyphosate. Although these studies showed that PPP can adversely affect vegetation adjacent to agricultural areas, they lacked data on residue levels on the vegetation. Studies on the amount of spray drift after the application of PPP in different heights to field crops found that the amount of spray drift decreases with increasing height with highest residue levels (up to $2 \%$ of the applied amount) at $0-1.5 \mathrm{~m}$ above the ground (Løfstrøm et al. 2013; Phillips and Miller 1999; Zande et al. 2014b). The aforementioned studies relate to the application of PPP to field crops. There are also studies investigating spray drift after application of PPP to tall growing crops which reported a two- to threefold variation in the residues depending on the application technique and growth stage (Grella et al. 2017; Zande et al. 2014a). Overall, the lack of studies describing the residue levels on food crops grown near agricultural areas hampers an assessment of potential consumer risks.

The current pesticide registration process ignores pesticide residues reaching non-target food crops adjacent to agricultural areas, which are dependent, e.g., on the application rate and technique, meteorological conditions, the surface area to volume/mass ratio, and the crop surface (Bates 1990; Maclachlan and Hamilton 2010). Toxicological reference values define the exposure levels that are acceptable for consumers, e.g., the acute reference dose (ARfD), which is the estimated amount of substance a consumer can ingest on a single day without any health effects, and the acceptable daily intake (ADI), which is the estimated daily amount of a substance taken up without any health effects over a lifetime. For a PPP to be authorized, the dietary exposure is required to be lower than the ARfD and the ADI (Bundesinstitut für Risikobewertung 2015; Food and Agriculture Organization of the United Nations and World Health Organization 2008; Verordnung (EG) Nr. 1107/2009). Another limit value is the MRL, which is the highest legally allowed level of a pesticide residue on commodities put on the market. It is derived under consideration of the most critical good agricultural practice and set sufficiently high to accommodate for potential residues following the appropriate use of a PPP (Bundesinstitut für Risikobewertung 2015; Verordnung (EG) Nr. 1107/2009). For substance/food commodity combinations without a specific MRL, a default MRL of $0.01 \mathrm{mg} \mathrm{kg}^{-1}$ applies (Regulation (EC) No 396/2005). Residue levels found on food crops can be compared to the MRL and, after inclusion of consumption data, with the ADI and ARfD.

To determine the residue levels of PPP on food crops due to spray drift in gardens adjacent to agricultural areas, we simulated the application of PPP to field crops and to tall growing crops, respectively, in a wind tunnel and measured the amount of spray drift on food crops and on petri dishes located on the ground in the non-target area. For both crop types, commercially available spray booms and nozzles 
were used under conditions intending to approximate the actual use condition in the field. Based on the amounts of tracer recovered in the wind tunnel experiments, a model was developed to estimate potential residues in neighbouring food crops using actual rates of pesticides from registered PPP. Finally, comparisons with established MRLs and conclusions on the consumer exposure were made.

\section{Material and methods}

\subsection{Experimental setup}

The study was conducted using a wind tunnel of the RLP AgroScience $\mathrm{GmbH}$ in Rhineland-Palatinate in Germany. The arc-shaped wind tunnel was $55 \mathrm{~m}$ long, $6.5 \mathrm{~m}$ wide and up to $3.1 \mathrm{~m}$ high. At the end of the tunnel, 26 synchronously working fans were installed. They could produce wind velocities up to $5 \mathrm{~m} \mathrm{~s}^{-1}$. For the experiments, a wind velocity of $4 \mathrm{~m} \mathrm{~s}^{-1}$ was used. The wind tunnel was separated into a target area, which was $25 \mathrm{~m}$ long and $4 \mathrm{~m}$ wide and located directly in front of the fans, and an equally sized non-target area behind the target area. The target area was bare soil to allow a laminar wind flow. In total, the experimental wind tunnel parameters represent a static environment, potentially resulting in maximum spray drift comparable to field conditions. For the experiments, a spray boom (Ebinger $\mathrm{GmbH}$ ) was installed between the target and the non-target area (Fig. 1). Applications of the test solution were always performed in the morning hours under comparable exterior weather conditions. The experiments were conducted with two different test systems. The first test system simulated the application of PPP to field crops (hereafter: test system "field crops"). Nine downwards directed flat fan nozzles (XR 11003 -VK, TeeJet) were used with a nozzle spacing of $50 \mathrm{~cm}$ and a nozzle height of $110 \mathrm{~cm}$ above the ground. The spraying boom was placed perpendicular to the wind direction in

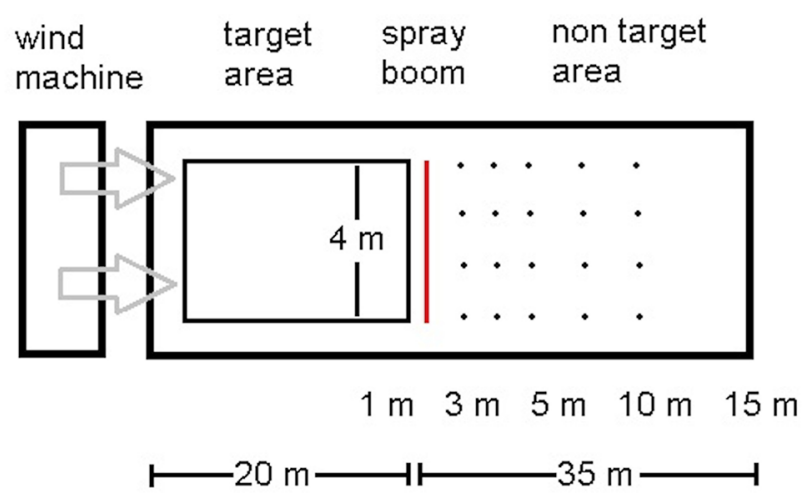

Fig. 1 Experimental setup of the wind tunnel experiments the wind tunnel. We distributed 20 sampling points in the non-target area at multiple distances of $1-15 \mathrm{~m}$ to the spray boom (four sampling points with $1 \mathrm{~m}$ spacing per distance). The experimental setup is based on the determination of basic drift values, which shows the highest residue levels near the spray boom (Bundesamt für Verbraucherschutz und Lebensmittelsicherheit 2020; Ganzelmeier et al. 1995; Rautmann et al. 2001). Therefore, we expected considerable residue levels on food crops near the spray boom and limited the test area to $10 \mathrm{~m}$. The second test system simulated the application of PPP to tall growing crops (test system "tall growing crops"). These experiments were conducted with 13 downwards directed hollow cone nozzles (ATR 80 , Albuz) with a nozzle spacing of $35 \mathrm{~cm}$ and a nozzle height of $175 \mathrm{~cm}$. The sampling points were distributed as described for the first test system, but with sampling points at $15 \mathrm{~m}$ distance instead of $1 \mathrm{~m}$ distance, since the basic drift values show higher residue levels even in longer distances after the application of PPP to tall growing crops (Bundesamt für Verbraucherschutz und Lebensmittelsicherheit 2020; Ganzelmeier et al. 1995; Rautmann et al. 2001) A pyranine concentration of $0.15 \mathrm{~g} \mathrm{l}^{-1}$ was applied for 3-30 s, increasing the duration with the distance of the model crop to the spray boom. Before starting the experiments, the droplet size distribution was measured with a laser precipitation monitor (Thies Clima) with a measuring range of $0.16-8 \mathrm{~mm}$. The measurement was performed with one of the nozzles used and at the application height intended for the experiments (Flat fan nozzle: $100 \mathrm{~cm}$, hollow cone nozzle: $175 \mathrm{~cm}$ ). The droplet sizes generated by the flat fan nozzle were mainly distributed between $0.25-1.00 \mathrm{~mm}$, those generated by the hollow cone nozzle between $0.25-0.75 \mathrm{~mm}$. For both nozzles most droplets had a diameter between 0.50 and $0.75 \mathrm{~mm}$ (Fig. 2).

\subsection{Pyranine as spray drift tracer}

The fluorescence dye pyranine $120 \%$ (Simon and Werner $\mathrm{GmbH}$, batch number: CHT91115) was used as a tracer for the experiments as recommended by Nairn and Forster (2015) and Herbst and Wygoda (2006) because of its high water solubility and its low limit of detection. Pyranine has its excitation maximum at $402 \mathrm{~nm}$ and its emission maximum at $504 \mathrm{~nm}$ (Herbst and Wygoda 2006). $300 \mu$ of each sample were pipetted into a 96-well plate to measure the fluorescence with the fluorescence reader FLx800 (BioTek). A $400 / 30 \mathrm{~nm}$ filter was used for the excitation and a 508/20 nm filter for the emission. Prior to the experiments in the wind tunnel, pyranine was tested regarding its photo stability in the wind tunnel and its quantitative wash-off from different surfaces. Tomato and strawberry fruits were directly treated with defined amounts of pyranine solution and left $20 \mathrm{~min}$ for drying in the wind tunnel. Afterwards, samples were 


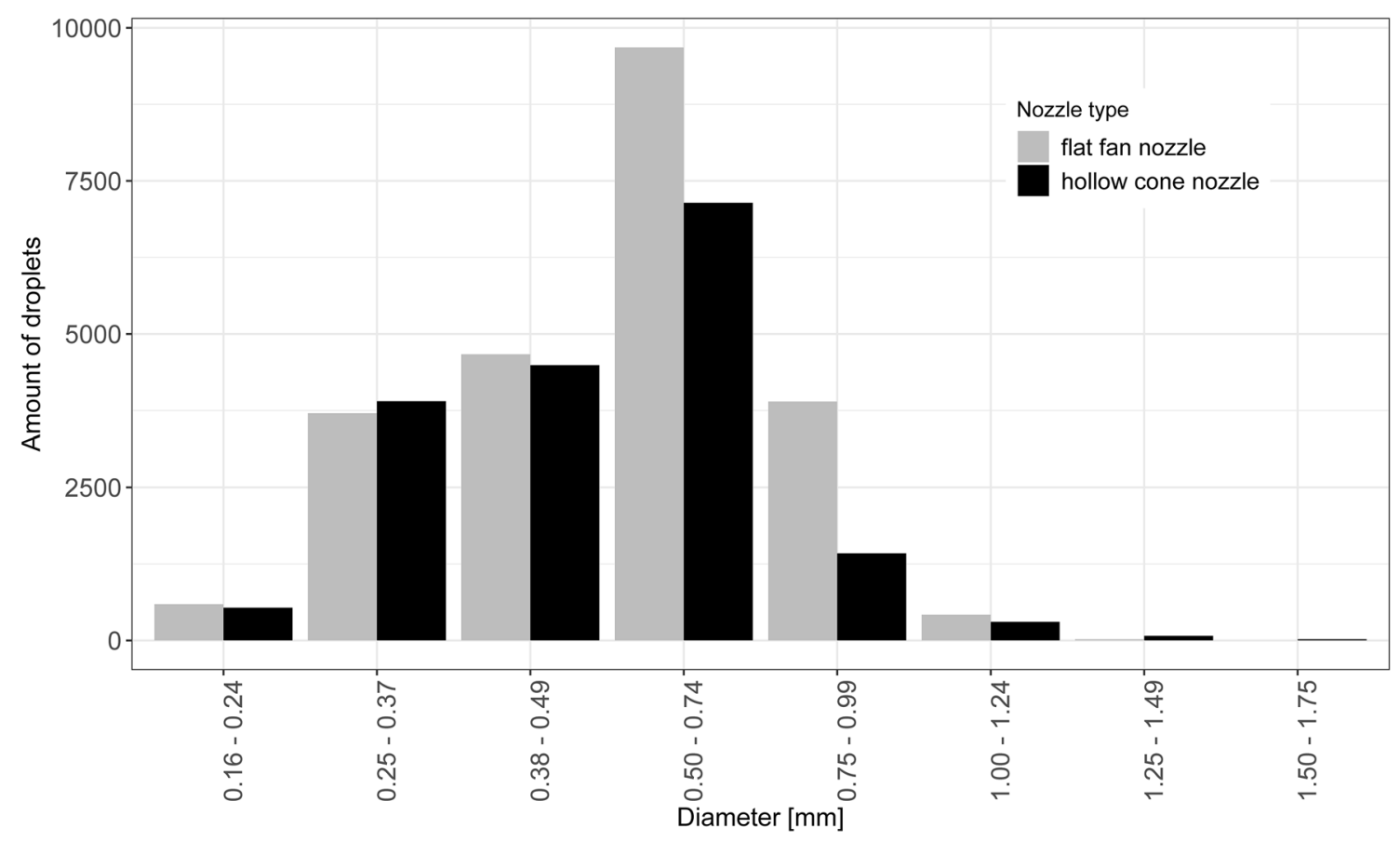

Fig. 2 Droplet size distribution

analysed and surface extraction showed recoveries of $>95 \%$ of the expected amounts. In addition, the photo stability of the tracer was tested using petri-dishes placed in the wind tunnel for $20 \mathrm{~min}$. Again, recovered pyranine amounts represented $>99 \%$ of the applied concentrations.

\subsection{Model crops}

Three model crops were used for the experiments. They were placed in the non-target area to simulate the vegetation in a garden area adjacent to agriculture. The criteria for the selection of the model crops were:

- the edible part is growing above the surface,

- the selected plants differ in their morphology,

- the plants are important with respect to their occurrence in gardens (Bundesverband Deutscher Garten-freunde e.V. 2008) and with respect to consumed amounts (Bundesministerium für Ernährung, Landwirtschaft und Verbraucherschutz and Max Rubner-Institut, Bundesforschungsinstitut für Ernährung und Lebensmittel 2008),

- the edible part is directly exposed to spray drift and no peeling is required before consumption.

Based on these criteria, strawberries, tomatoes and lettuce were selected as model crops. The tomatoes were cultivated to a height of $160 \mathrm{~cm}$, the lettuce was obtained freshly harvested from a farmer with an average weight of $333 \mathrm{~g}$ (average weight of 20 lettuces) and the strawberries were cultivated to a height of $20 \mathrm{~cm}$.

\subsection{Experimental procedure}

The experiments were conducted separately for each model crop and distance. The plants were placed on the sampling points. A blank petri dish was placed in front of each plant to measure ground deposition. The spray solution with a pyranine concentration of $0.15 \mathrm{~g} \mathrm{l}^{-1}$ was filled into the spray tank (Spray-Matic 20S, Birchmeier) and a pressure of 4 bar was built up at the tank. The wind velocity was adjusted to $4 \mathrm{~m} \mathrm{~s}^{-1}$ and measured at the spray boom with an anemometer (PL-130 AN, Voltcraft). The spray solution was applied for 3-30 s, increasing the duration with distance of the model crop to the spray boom to ensure findings within the validated measurement range of the used analytical fluorescence method. After the application, the petri dishes were collected within ten minutes and stored in the dark. Four to six strawberries and five tomatoes completely exposed to spray drift were sampled per sampling point in bottles with 100 or $500 \mathrm{ml}$ of water, and analyzed in total. For tomatoes, fruits located approximately $75 \mathrm{~cm}$ above the ground were sampled. Every lettuce head was completely dipped into a bucket with 31 of water. The bottles and buckets were thoroughly shaken and a sample was taken from each to measure the fluorescence of pyranine. The petri dishes were quantitatively washed with $50 \mathrm{ml}$ water and the fluorescence was measured. The fresh weight of the tomatoes and the 
strawberries was determined for each sampling point after taking the sample. In contrast, the average fresh weight of 20 heads of lettuce was determined prior to the experiments.

To avoid potential cross contaminations, a single operator cut all fruit samples from the plants using scissors and let the specimen fall directly into an appropriate vessel. Scissors were cleaned after each plant. Lettuce heads and petri dishes were collected by hand wearing new gloves for each sample. After finalization of an experiment, reusable equipment was thoroughly washed. Target plants and lettuce heads were always untreated and newly placed.

\subsection{Determination of the residue levels}

For the determination of the concentration of the tracer in each sample, a calibration with an aliquot of the applied tank mixture was performed for each experiment. The range of recovery fortifications ranged from 0.07875 to $3 \mathrm{mg}^{-1}$. The concentrations were normalized by proportional scaling of measured residue levels following actual application times of 3-30 s to a nominal application time of $10 \mathrm{~s}$. Afterwards, these values were converted into the amount of pyranine expressed per mass $\left(\mu \mathrm{g} \mathrm{g}^{-1}\right)$ for the fruits and per area $\left(\mu \mathrm{g} \mathrm{cm}^{-2}\right)$ for the petri dishes.

To compare the ground deposition of the two test systems, the mean deposition in the petri dishes for each distance was calculated from the experiments with strawberries, lettuce and tomatoes, separately for both test systems.

\subsection{Data analysis and calculation of residue levels for a case study.}

We conducted a linear regression analysis in $\mathrm{R}$ (Version 3.3.1.) to predict the amount of pyranine per mass found on the food crops from the amount of pyranine per area in the petri dishes. Prior to analysis, both the response and the predictor variable were log-transformed using the natural logarithm to meet assumptions of the linear model (homoscedasticity, linear relationship):

$\ln (y)=b \ln (x)+a$

where (y) is the amount of pyranine on the food crops, (x) the amount of pyranine in the petri dishes and (a) and (b) are regression parameters. The assumptions of the linear models were tested visually.

We used a reformulation of Eq. (1):

$y=e^{a} \times x^{b}$

to directly estimate the amount of PPP residues on food crops based on the ground deposition, which is for example described by the basic drift values. This was done for a case study with lettuce, strawberries and tomatoes at a

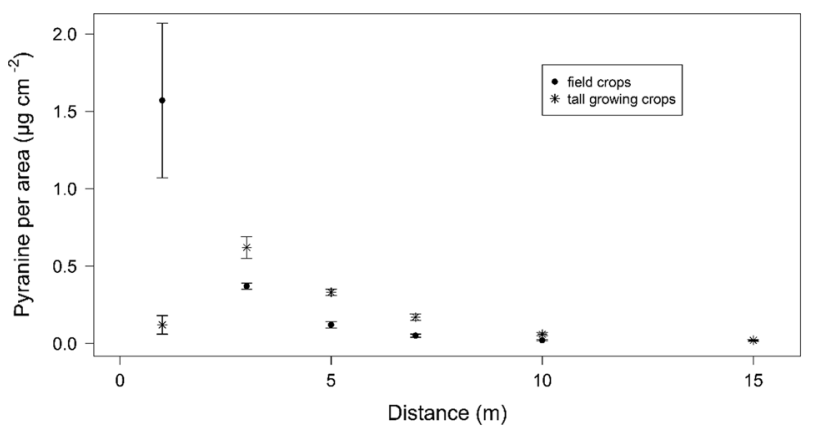

Fig. 3 Mean deposition in the petri dishes separated for each test system

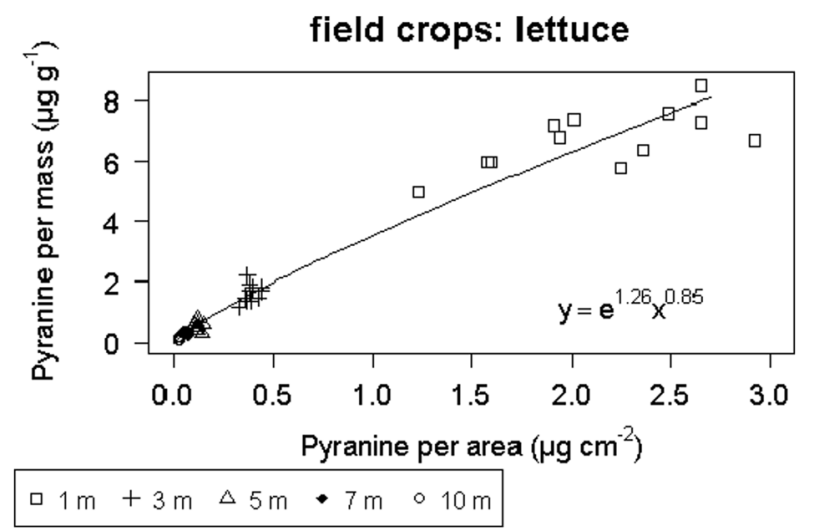

Fig. 4 Pyranine residues in petri dishes and on lettuce separated for the distances and with regression line, test system: field crops

distance of $5 \mathrm{~m}$ to field crops. In this case study, the field crop is assumed to be treated with a pesticide with a common application rate of $1.3 \mathrm{~kg}$ active ingredients (a.i.) per ha (Bayerische Landesanstalt für Landwirtschaft, Institut für Pflanzenschutz 2020). The results were compared with the default MRL of $0.01 \mathrm{mg} \mathrm{kg}^{-1}$ for many pesticides (Regulation [EC] No 396/2005).

This calculation was also conducted for other distances $(1 \mathrm{~m}, 5 \mathrm{~m}, 10 \mathrm{~m}, 15 \mathrm{~m}$ and $20 \mathrm{~m})$ and the results were compared to residues measured in agricultural food commodities under field conditions compiled by Maclachlan and Hamilton (2010). They measured residue levels for lettuce, strawberries and tomatoes at the day of application. The residue levels expressed in $\mathrm{mg} \mathrm{kg}^{-1}$ and normalized to an application rate of $1 \mathrm{~kg}$ a.i. $\mathrm{ha}^{-1}$, were converted to the example application rate of $1.3 \mathrm{~kg}$ a.i. $\mathrm{ha}^{-1}$ and adjusted to the expected distance-related residue levels by means of the basic drift values. Although these values relate to the ground deposition, we assumed that the percentage loss of pesticide residues with distance is the same for the ground deposition and the deposition on plants grown at the respective location. 


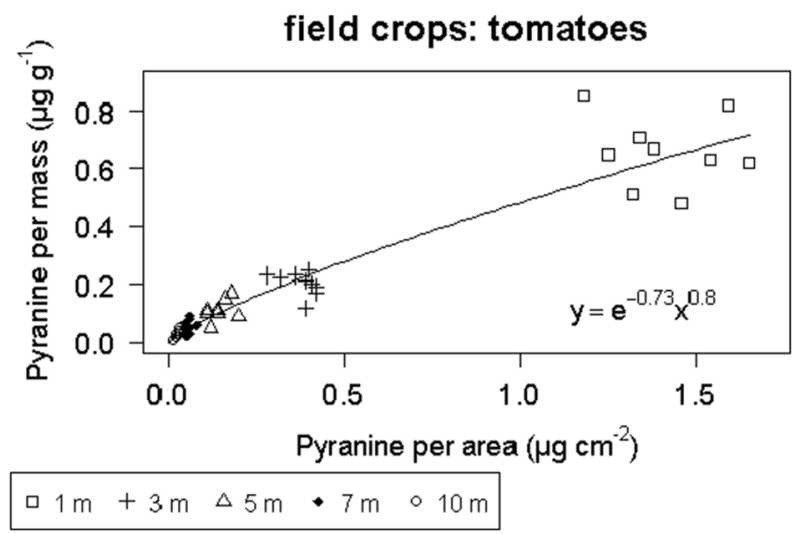

Fig. 5 Pyranine residues in petri dishes and on tomatoes separated for the distances and with regression line, test system: field crops

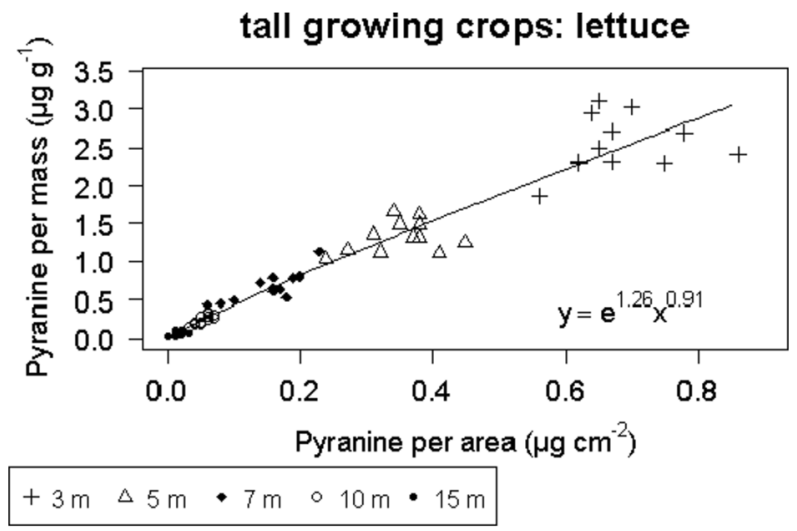

Fig. 6 Pyranine residues in petri dishes and on lettuce separated for the distances and with regression line, test system: tall growing crops

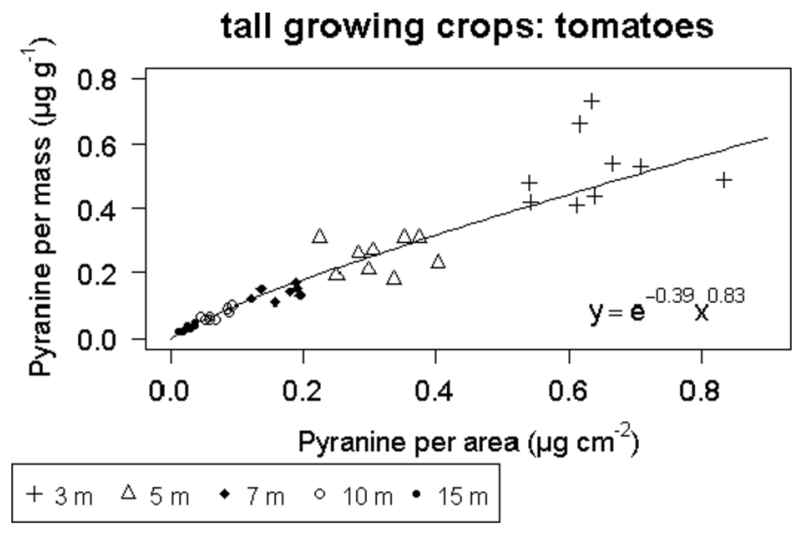

Fig. 7 Pyranine residues in petri dishes and on tomatoes separated for the distances and with regression line, test system: tall growing crops

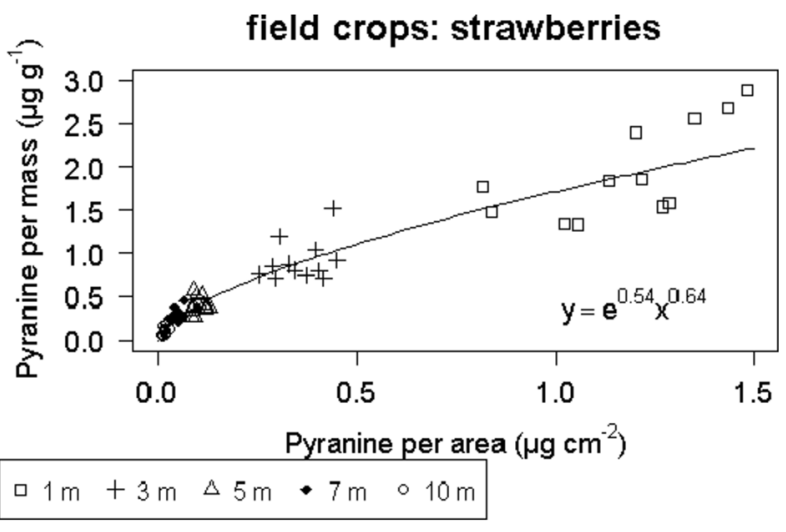

Fig. 8 Pyranine residues in petri dishes and on strawberries separated for the distances and with regression line, test system: field crops

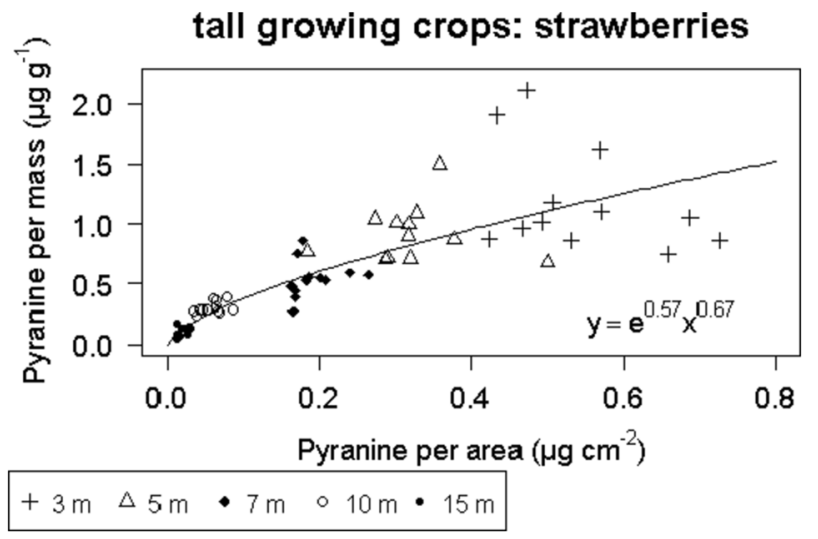

Fig. 9 Pyranine residues in petri dishes and on strawberries separated for the distances and with regression line, test system: tall growing crops

Since the relation between distance and ground deposition was robustly described (Bundesamt für Verbraucherschutz und Lebensmittelsicherheit 2020; Ganzelmeier et al. 1995; Rautmann et al. 2001), the spray drift affecting a specified ground area would also be intercepted by crops present.

\section{Results}

\subsection{Deposition on the ground}

The amount of pyranine in the petri dishes was higher in the test system tall growing crops than in the test system field crops, except for the distance of $1 \mathrm{~m}$ (Fig. 3). In both test systems, the recovered amount of pyranine was 
log-transformed and linear regression gave the best compliance with the data, suggesting exponential decrease of the ground deposition with increasing distance. Furthermore, we observed in experiments with the test system field crops that the droplets in the petri dishes at $1 \mathrm{~m}$ distance to the spray boom were considerably larger than at the other distances.

\subsection{Residue levels on the food crops}

In general, the amount of pyranine on the crops was higher in the test system tall growing crops than in the test system field crops for a given distance. In the test system field crops, the highest residue levels were found on lettuce (up to $8.5 \mu \mathrm{g} \mathrm{g}^{-1}$ ), followed by strawberries (up to $2.9 \mu \mathrm{g} \mathrm{g}^{-1}$ ) and tomatoes (up to $0.9 \mu \mathrm{g} \mathrm{g}^{-1}$ ) (Figs. 4, 5). The highest amounts of pyranine were found at $1 \mathrm{~m}$ distance to the spray boom. Furthermore, in the test system field crops, a strong decrease was observed between the data points of the $1 \mathrm{~m}$ and the $3 \mathrm{~m}$ distance. In the test system tall growing crops the highest amounts of pyranine were found at $3 \mathrm{~m}$ distance to the spray boom. We found up to $3.1 \mu \mathrm{g} \mathrm{g}^{-1}$ on lettuce, up to $2.1 \mu \mathrm{g} \mathrm{g}^{-1}$ on strawberries and up to $0.7 \mu \mathrm{g} \mathrm{g}^{-1}$ on tomatoes (Figs. 6, 7).

The amount of pyranine on the food crops was strongly positively related to the amount of pyranine in the petri dishes, with minor non-explained variance (all $\mathrm{R}^{2}$ between 0.88 and 0.97). The relationships flattened with increasing amount of pyranine, in particular for strawberries (Figs. 8, 9).

\subsection{Comparison of the experimentally derived residue levels with the default MRL and measured residue levels}

As an example, we calculated the residue levels on the three food crops at some distances to field crops, which were treated with a pesticide with an application rate of $1.3 \mathrm{~kg}$ a.i. $\mathrm{ha}^{-1}$. To compare the results with the default MRL, we considered the residue levels at $5 \mathrm{~m}$ distance, representing the minimum distance between tall crops and adjacent areas. According to the basic drift values (Bundesamt für Verbraucherschutz und Lebensmittelsicherheit 2020; Ganzelmeier et al. 1995; Rautmann et al. 2001), the ground deposition at this distance is $0.07 \mu \mathrm{g}$ a.i. $\mathrm{cm}^{-2}$, which

Table 1 Comparison of the residue levels based on the wind tunnel experiments and the residue levels based on Maclachlan and Hamilton (2010)

\begin{tabular}{|c|c|c|c|c|c|c|c|c|c|}
\hline \multirow[t]{2}{*}{ Distance (m) } & \multicolumn{3}{|c|}{$\begin{array}{l}\text { Values estimated following spray drift based on wind } \\
\text { tunnel experiments }\end{array}$} & \multicolumn{6}{|c|}{$\begin{array}{l}\text { Comparison with values based on the publication of Maclachlan and } \\
\text { Hamilton }(2010)\left(\mu \mathrm{g} \mathrm{g}^{-1}\right)\end{array}$} \\
\hline & $\begin{array}{l}\text { Basic drift } \\
\text { values }\left(90^{\text {th }}\right. \\
\text { percentile) }(\%)\end{array}$ & $\begin{array}{l}\text { Ground deposi- } \\
\text { tion based on } \\
\text { basic drift values } \\
\left(\mu \mathrm{g} \mathrm{cm}^{-2}\right)\end{array}$ & $\begin{array}{l}\text { Residues on } \\
\text { food crops based } \\
\text { on wind tunnel } \\
\text { trials }\left(\mu \mathrm{g} \mathrm{g}^{-1}\right)\end{array}$ & Minimum & Maximum & Median & Mean & $90^{\text {th }}$ percentile & $95^{\text {th }}$ percentile \\
\hline \multicolumn{10}{|l|}{ Lettuce } \\
\hline 0 & 100 & 13 & 31.19 & 0.74 & 236.60 & 24.70 & 42.25 & 91.00 & 135.20 \\
\hline 1 & 2.77 & 0.36 & 1.48 & 0.02 & 6.55 & 0.68 & 1.17 & 2.52 & 3.75 \\
\hline 5 & 0.57 & 0.07 & 0.39 & 0.00 & 1.35 & 0.14 & 0.24 & 0.52 & 0.77 \\
\hline 10 & 0.29 & 0.04 & 0.22 & 0.00 & 0.69 & 0.07 & 0.12 & 0.26 & 0.39 \\
\hline 15 & 0.20 & 0.03 & 0.16 & 0.00 & 0.47 & 0.05 & 0.08 & 0.18 & 0.27 \\
\hline 20 & 0.15 & 0.02 & 0.12 & 0.00 & 0.35 & 0.04 & 0.06 & 0.14 & 0.20 \\
\hline \multicolumn{10}{|l|}{ Strawberries } \\
\hline 0 & 100 & 13 & 8.86 & 0.16 & 73.71 & 1.95 & 6.23 & 7.80 & 31.20 \\
\hline 1 & 2.77 & 0.36 & 0.89 & 0.00 & 2.04 & 0.05 & 0.17 & 0.22 & 0.86 \\
\hline 5 & 0.57 & 0.07 & 0.32 & 0.00 & 0.42 & 0.01 & 0.04 & 0.04 & 0.18 \\
\hline 10 & 0.29 & 0.04 & 0.21 & 0.00 & 0.21 & 0.01 & 0.02 & 0.02 & 0.09 \\
\hline 15 & 0.20 & 0.03 & 0.17 & 0.00 & 0.15 & 0.00 & 0.01 & 0.02 & 0.06 \\
\hline 20 & 0.15 & 0.02 & 0.14 & 0.00 & 0.11 & 0.00 & 0.01 & 0.01 & 0.05 \\
\hline \multicolumn{10}{|l|}{ Tomatoes } \\
\hline 0 & 100 & 13 & 3.75 & 0.01 & 13.65 & 0.59 & 1.01 & 1.82 & 3.25 \\
\hline 1 & 2.77 & 0.36 & 0.21 & 0.00 & 0.38 & 0.02 & 0.03 & 0.05 & 0.09 \\
\hline 5 & 0.57 & 0.07 & 0.06 & 0.00 & 0.08 & 0.00 & 0.01 & 0.01 & 0.02 \\
\hline 10 & 0.29 & 0.04 & 0.03 & 0.00 & 0.04 & 0.00 & 0.00 & 0.01 & 0.01 \\
\hline 15 & 0.20 & 0.03 & 0.03 & 0.00 & 0.03 & 0.00 & 0.00 & 0.00 & 0.01 \\
\hline 20 & 0.15 & 0.02 & 0.02 & 0.00 & 0.02 & 0.00 & 0.00 & 0.00 & 0.00 \\
\hline
\end{tabular}

Bold values indicate the current study results 
corresponds to $0.39 \mathrm{mg}$ a.i. $\mathrm{kg}^{-1}$ on lettuce, $0.32 \mathrm{mg}$ a.i. $\mathrm{kg}^{-1}$ on strawberries and $0.06 \mathrm{mg}$ a.i. $\mathrm{kg}^{-1}$ on tomatoes. Therefore, the calculated residue levels indicate an exceedance of the default MRL of $0.01 \mathrm{mg} \mathrm{kg}^{-1}$.

The comparison of the calculated residue levels on food commodities based on the wind tunnel experiments with observed ranges of residue levels following actual field use of pesticides published by Maclachlan and Hamilton (2010) show that the calculated residue levels are within the expected range of residue levels under real conditions. For strawberries and tomatoes, the calculated residue levels were higher than the $95^{\text {th }}$ percentile and mostly in the range of the maximum and for lettuce they were between the mean and the $90^{\text {th }}$ percentile (Table 1). For strawberries, tomatoes and lettuce, for a distance of $0 \mathrm{~m}$ to the spray boom the residue levels are in the range of the $90^{\text {th }}$ percentile, in the range of the $95^{\text {th }}$ percentile and between the median and the mean, respectively.

\section{Discussion}

\subsection{The influence of droplet size and spray boom height on the distribution of spray drift}

The residual concentrations were highest on lettuce, followed by strawberries and lowest on tomatoes for both test systems. This may be caused by the larger surface of lettuce due to its leaf morphology, while strawberries exhibit a higher surface to volume/mass ratio than tomatoes, which influences the residue levels (Bates 1990). Moreover, strawberries were harvested almost at ground level, whereas tomatoes (total plant height $1.6 \mathrm{~m}$ ) were harvested at about $75 \mathrm{~cm}$. Significant amounts of droplets may have sedimented below this height, which means that strawberries, in contrast to tomatoes, are still exposed to the spray plume in larger distances. Measurements of pesticide residues in treated fruits and vegetables also show higher residue levels in strawberries than in tomatoes (Ahmed and Ismail 1995; Safi et al. 2002), and the highest residue levels in lettuce (Maclachlan and Hamilton 2010).

The absolute residue levels decreased strongly from 1 to $3 \mathrm{~m}$ in the test system field crops (Figs. 4, 5, 8). We suggest that this is most likely explained by the droplet size. At a distance of $1 \mathrm{~m}$, the droplets in the petri dishes were considerably larger than at the other sampling points. The spray plume consists of small and large droplets as shown for both nozzles (Fig. 2). Due to their mass, large droplets transport more pyranine and deposit faster than small droplets, primarily within the $1 \mathrm{~m}$ distance (Bird et al. 1996; Byass and Lake 1977; Carlsen et al. 2006). By contrast, smaller droplets exhibit a distribution of deposition distances and are primarily responsible for the pyranine concentrations found at distances $>1 \mathrm{~m}$.

\subsection{Comparison of the test systems with outdoor applications}

Results obtained from wind tunnel experiments are conservative as the wind flow in open land is characterized by turbulences due to different surface structures such as bushes and trees. Consequently, the spray plume can be directed in multiple directions. Furthermore, in open lands, wind velocity and direction vary over time. In the wind tunnel, vegetation was absent in the target area and the tunnel is closed at three sides leading to nearly laminar airflow (Goossens et al. 2000). The plants on the sampling points were adjusted in a way that the edible part was exposed to spray drift. Also filtering effects of fences and hedges surrounding allotments and gardens were ignored in the test systems. Another aspect is the orientation of the spray boom, which was placed perpendicular to the wind direction in the wind tunnel. This layout is expected to be most susceptible to spray drift compared to other orientations. Therefore, the residue levels estimated based on this work likely represent the upper range of the residues expected under realistic field conditions which was confirmed by comparison of the results with measured residue levels (Maclachlan and Hamilton 2010).

The test system field crops is, except for the artificial wind conditions discussed above, widely compliant with applications in the open field. In outdoor applications and also in the experimental wind tunnel setup, the nozzles are directed to the ground. Moreover, applications of PPP to bare soils are common in agriculture, e.g., with pre-emergence herbicides. Overall, this suggests that the results may be extrapolated to the field.

To simulate the application of a PPP to tall growing crops, the spray boom was set to a height of $175 \mathrm{~cm}$. Other than during real PPP applications in tall crops, the nozzles were adjusted to the ground in this setup, as no target crop was available to filter a part of the spray plume. The selected setup without a target crop ignores that when approaching a structure (e.g., wall, hedge), the wind moves upwards over the obstacle. This induces strong turbulences in airflow (Davis et al. 1994). The missing filter effect and the lack of turbulent air flow needs to be considered when extrapolating the test system tall growing crops to realistic outdoor conditions.

The basic drift values for field crops are considerably smaller than those for tall growing crops (Bundesamt für Verbraucherschutz und Lebensmittelsicherheit 2020; Ganzelmeier et al. 1995; Rautmann et al. 2001). These differences contrast with those from the wind tunnel experiments. The ground deposition (Fig. 3) decreased equally for both test systems, but spatially shifted. The data suggests that the test system tall growing crops can be considered as a variation of the test system field crops. Although the position of the spray boom and the selected nozzles probably 
resulted in a deviating droplet spectrum and larger height of the spray plume, environmental parameters were too similar between both test systems to address differences in the field. The higher position of the spray boom resulted in quantifiable residues at a distance of $15 \mathrm{~m}$, thus, the comparison of the test systems confirms that the height of the spray boom has a great influence on spray drift (Byass and Lake 1977; Nordby and Skuterud 1975; Nuyttens et al. 2007). The higher the spray boom, the higher the residue levels caused by spray drift. Also, the pattern for strawberries (Figs. 8, 9) and lettuce (Figs. 4, 6) and the related equations were similar in both test systems. The different pattern observed for tomatoes (Figs. 5, 7) can be explained by the fact that tomatoes were harvested higher above the ground. Thus, a large part of the spray plume in the test system field crops passed below the fruits. In the tall growing crop test system, the tomato fruits were directly affected by the spray plume, leading to higher residues. Overall, the variations introduced to the tall growing crop system resulted in a weaker approximation of conditions in the field. For future experiments, appropriate means to simulate filter structures and obstacles causing air turbulences should be considered.

\subsection{Extrapolation of the results to the field situation}

Stadler and Regenauer (2005) cautioned against extrapolating residue levels gained in the wind tunnel directly to the field situation, because the spray plume decreases faster in the wind tunnel than in the open field. This matches our observations in preliminary studies. However, the ratio between ground and plant deposition can be considered identical for the wind tunnel and the field situation, and the ratio obtained in the wind tunnel can therefore be used together with the basic drift values to estimate residue levels on strawberries, lettuce and tomatoes in the field situation. The comparison of the calculated residue levels with the measured residue levels on food crops compiled by Maclachlan and Hamilton (2010) suggests that the results of this study provide realistic estimates, though in the upper range.

In the case study scenario, a pesticide application with a common application rate resulted in the exceedance of the default MRL at a distance of $5 \mathrm{~m}$ from the applied area. However, farmers are only obliged to keep $2 \mathrm{~m}$ distance to neighboring areas during the application of PPPs to field crops (Bundesamt für Verbraucherschutz und Lebensmittelsicherheit 2016), which means that also in compliance with good agricultural practice, MRLs may be exceeded. It has long been known that spray drift can lead to measurable pesticide residues in neighbouring crops (European Commission, Directorate-General for Health and Food Safety 2017; European Food Safety Authority 2018; Seiler et al. 2007) and it has also been suspected that spray drift may lead to MRL exceedances (European Crop Protection. 2014; European Food Safety Authority [EFSA] 2021), which is supported by the results of this study.

\subsection{Extrapolation of the results to other food commodities}

Extrapolation of the results to other crops or food commodities is difficult without further knowledge of the potential deposition of the spray drift on these crops. The surface to volume ratio of fruits strongly influences the final residue concentration (Bates 1990). With increasing size of the fruit, the volume increases faster than the surface area. For example, $200 \mathrm{~g}$ small strawberries have a larger total surface area than $200 \mathrm{~g}$ large tomatoes. Consequently, for a given weight the amount of substance deposited is smaller for large fruits. In addition, the harvesting height influences the extrapolation, because it directly affects the contact with the spray plume. Overall, our results may only be extrapolated to other food crops of similar size and harvesting height.

\section{Conclusions}

This study provides a first approach to quantify spray driftbased residues on food commodities grown adjacent to field crops. First estimations of expected residue levels on tomatoes, lettuce and strawberries are provided and it was shown that these could exceed regulatory levels, warranting further in-depth studies, e.g., involving direct measurements in a realistic outdoor environment. It is recommended to screen all approved PPP according to the model described in this study for potential MRL exceedances. In parallel, the resulting acute dietary exposure should also be determined and compared to respective ARfD values to predict possible consumer health risks. A correlation with residues measured under field conditions suggests that the results of this study provide realistic worst case estimates of residues on food commodities, at least for the field crop scenario. With the selected experimental setup for tall growing crops, realistic estimates of pesticide residue concentrations on food crops cultivated in adjacent areas was not achieved. Especially the implementation of filter structures and obstacles to cause turbulences of the air flow could significantly improve approximation of the test system to field conditions. We recommend a more realistic adaptation of the test system tall growing crops or the conduct of supervised trials with such crops in the field.

Acknowledgements The authors thank the employees of RLP AgroScience GmbH, Institute for Agroecology (Neustadt/Wstr.) for the help with the wind tunnel experiments and the assistance with the chemical analysis. 
Funding Open Access funding enabled and organized by Projekt DEAL.

\section{Declarations}

Conflict of interest On behalf of all authors, the corresponding author states that there is no conflict of interest.

Open Access This article is licensed under a Creative Commons Attribution 4.0 International License, which permits use, sharing, adaptation, distribution and reproduction in any medium or format, as long as you give appropriate credit to the original author(s) and the source, provide a link to the Creative Commons licence, and indicate if changes were made. The images or other third party material in this article are included in the article's Creative Commons licence, unless indicated otherwise in a credit line to the material. If material is not included in the article's Creative Commons licence and your intended use is not permitted by statutory regulation or exceeds the permitted use, you will need to obtain permission directly from the copyright holder. To view a copy of this licence, visit http://creativecommons.org/licenses/by/4.0/.

\section{References}

Ahmed MT, Ismail SMM (1995) Residues of methomyl in strawberries, tomatoes and cucumbers. J Pestic Sci 44:197-199

Bates JAR (1990) IUPAC Reports on Pesticides - The prediction of pesticide residues in crops by the optimum use of existing data. Pure Appl Chem 62(2):337-350

Bayerische Landesanstalt für Landwirtschaft, Institut für Pflanzenschutz (2020) Informationen zum Wirkstoff Glyphosat

Bird SL, Esterly DM, Perry SG (1996) Off-target deposition of pesticides from agricultural aerial spray applications. J Environ Qual 25:1095-1104

Boutin C, Strandberg B, Carpenter D, Mathiassen SK, Thomas PJ (2014) Herbicide impact on non-target plant reproduction: what are the toxicological and ecological implications? Environ Pollut 185:295-306

Bundesamt für Verbraucherschutz und Lebensmittelsicherheit (2016) Bekanntmachung über die Mindestabstände bei der Anwendung von Pflanzenschutzmitteln zum Schutz von Umstehenden und Anwohnern, die der Zulassung von Pflanzenschutzmitteln zugrunde gelegt werden (BVL 16/02/02). BAnz AT 20.05.2016 B5

Bundesamt für Verbraucherschutz und Lebensmittelsicherheit (2020) Sechste Bekanntmachung über die Abdrifteckwerte, die bei der Prüfung und Zulassung/Genehmigung von Pflanzenschutzmitteln herangezogen werden (BVL 20/02/05). BAnz AT 21.08.2020 B2

Bundesinstitut für Risikobewertung (2015) Questions and answers on residues of plant protection products in food. https://www.bfr. bund.de/cm/349/questions-and-answers-on-residues-of-plantprotection-products-in-food.pdf. Accessed 7 July 2020

Bundesministerium für Ernährung, Landwirtschaft und Verbraucherschutz, Max Rubner-Institut, Bundesforschungsinstitut für Ernährung und Lebensmittel (2008) Nationale Verzehrsstudie II

Bundesverband Deutscher Gartenfreunde e.V. (2008) Artenvielfalt: Biodiversität der Kulturpflanzen in Kleingärten

Byass JB, Lake JR (1977) Spray drift from a tractor-powered field sprayer. J Pestic Sci 8:117-126

Carlsen SCK, Spliid NH, Svensmark B (2006) Drift of 10 herbicides after tractor spray application. 2. Primary drift (droplet drift). Chemosphere 64(5):778-786
Dabrowski JM, Schulz R (2003) Predicted and measured levels of Azinphosmethyl in the Lourens River, South Africa: comparison of runoff and spray drift. Environ Toxicol Chem 22(3):494-500

Davis BNK, Brown MJ, Aj F, Yates TJ, Plant RA (1994) The effects of hedges on spray deposition and on the biological impact of pesticide spray drift. Ecotoxicol Environ Safe 27:281-293

De Schampheleire M, Nuyttens D, Baetens K, Cornelis W, Gabriels D, Spanoghe P (2009) Effects on pesticide spray drift of the physicochemical properties of the spray liquid. Precis Agric 10:409-420

European Commission, Directorate-General for Health and Food Safety (2017) Overview report-pesticide residue control in organic production

European Crop Protection (2014) Pesticide use and food safety

European Food Safety Authority (EFSA) (2021) The 2019 European Union report on pesticide residues in food. EFSA J 19(4):e06491

European Food Safety Authority (2018) Monitoring data on pesticide residues in food: results on organic versus conventionally produced food. EFSA Supporting Publication 2018:EN-1397. https:// doi.org/10.2903/sp.efsa.2018.EN-1397

Food and Agriculture Organization of the United Nations, World Health Organization (2008) Principles and methods for the risk assessment of chemicals in food. World Health Organization, 2009

Ganzelmeier H, Rautmann D, Spangenberg R, Streloke M, Herrmann M, Wenzelburger H-J, Walter H-F (1995) Studies on the spray drift of plant protection products: Results of a test program carried out throughout the Federal Republic of Germany. Mitteilungen aus der Biologischen Bundesanstalt für Land- und Forstwirtschaft Berlin-Dahlem 305

Gooijer YM, Hoftijser GQ, Lageschaar LCC, Oerlemans A, Scheepers PTJ, Kivits CM, Duyzer J, Gerritsen-Ebben MG, Figueiredo DM, Huss A, Krop EJM, Vermeulen RCG, Berg F van den, Holterman HJ, Jacobs CJM, Kruijne R, Mol JGJ, Wenneker M, Zande JC van de, Sauer PJJ (2019) Research on exposure of residents to pesticides in the Netherlands: OBO flower bulbs. Utrecht University

Goossens D, Offer Z, London G (2000) Wind tunnel and field calibration of five aeolian sand traps. Geomorphology 35:233-252

Grella M, Gallart M, Marucco P, Balsari P, Gil E (2017) Ground deposition and airborne spray drift assessment in vineyard and orchard: the influence of environmental variables and sprayer settings. Sustainability 9(728): $1-26$

Grisso R, Askew SD, McCall (2019) Nozzles: selection and sizing. Virginia Cooperative Extension, Virginia Tech 442-032

Herbst A, Wygoda H-J (2006) Pyranin-ein fluoreszierender Farbstoff für applikationstechnische Versuche. Nachrichtenblatt Des Deutschen Pflanzenschutzdienstes 58(3):79-85

Hofman V (2018) Spray equipment and calibration. Agricultural and Biosystems Engineering

Løfstrøm P, Bruus M, Andersen HV, Kjær C, Nuyttens D, Astrup P (2013) The OML-SprayDrift model for predicting pesticide drift and deposition from ground boom sprayers. J Pestic Sci 38(3):129-138

Maclachlan DJ, Hamilton D (2010) A new tool for the evaluation of crop residue trial data (day-zero-plus decline). Food Addit Contam Part A Chem Anal Control Expo Risk Assess 27(3):347-364. https://doi.org/10.1080/19440040903403024

Marrs RH, Frost A (1997) A microcosm approach to the detection of the effects of herbicide spray drift in plant Communities. J Environ Manag 50:369-388

Marrs RH, Aj F, Plant RA (1991) effects of herbicide spray drift on selected species of nature conservation interest: the effects of plant age and surrounding vegetation structure. Environ Pollut 69:223-235

Nairn JJ, Forster WA (2015) Photostability of pyranine and suitability as a spray drift tracer. N Z Plant Prot 68:32-37 
Nordby A, Skuterud R (1975) The effects of boom height, working pressure and wind speed on spray drift. Weed Res 14:385-395

Nuyttens D, de Schampheleire M, Baetens K, Sonck B (2007) The influence of operator-controlled variables on spray drift from field crop sprayers. Trans ASABE 50(4):1129-1140

Olszyk D, Pfleeger T, Shiroyama T, Blakeley-Smith M, Lee EH, Plocher M (2017) Plant reproduction is altered by simulated herbicide drift to constructed plant communities. Environ Toxicol Chem 36(10):2799-2813

Phillips JC, Miller PCH (1999) Field and wind tunnel measurements of the airborne spray volume downwind of single flat-fan nozzles. J Agric Eng Res 72:161-170

Rautmann D, Streloke M, Winkler R (2001) New basic drift values in the authorization procedure for plant protection products. Mitteilungen aus der Biologischen Bundesanstalt für Land- und Forstwirtschaft. In: Workshop on risk assessment and risk mitigation measures in the context of the authorization of plant protection products, pp 133-141

Regulation (EC) No 396/2005: of the European Parliament and of the Council on maximum residue levels of pesticides in or on food and feed of plant and animal origin and amending Council Directive 91/414/EEC (2005)

Safi JM, Abou-Foul NS, El-Nahhal YZ, El-Sebae AH (2002) Monitoring of pesticide residues on cucumber, tomatoes and strawberries in Gaza Governorates. Palestine Nahrung 46(1):34-39

Schweizer S, Kauf P, Höhn H, Naef A (2013) Abdrift-reduzierende Maßnahmen im Praxisversuch. Agrarforschung Schweiz 4:484-491
Seiler K, Erzinger F, Wyss GS (2007) Pestizidrückstände auf BioProdukten: Beurteilung der Kontaminationswege am Beispiel Bio-Wein

Stadler R, Regenauer W (2005) Drift studies - comparison of field and wind tunnel experiments. Commun Agric Appl Biol Sci 70(4):971-973

Strandberg B, Sørensen PB, Bruus M, Bossi R, Dupont YL, Link M, Damgaard CF (2021) Effects of glyphosate spray-drift on plant flowering. Environ Pollut 280:116953

Umweltbundesamt (2018) Umwelt und Landwirtschaft 2018

van de Zande JC, Butler Ellis MC, Wenneker M, Walklate PJ, Kennedy MC (2014a) Spray drift and bystander risk from fruit crop spraying. Asp Appl Biol 122:177-186

van de Zande JC, Michielsen JMGP, Stallinga H, van Velde P (2014b) Spray drift of drift reducing nozzle types spraying a bare soil surface with a boom sprayer. Asp Appl Biol 122:245-253

Verordnung (EG) Nr. 1107/2009 des Europäischen Parlaments und des Rates vom 21. Oktober 2009 über das Inverkehrbringen von Pflanzenschutzmitteln und zur Aufhebung der Richtlinien 79/117/ EWG und 91/414/EWG des Rates

Publisher's Note Springer Nature remains neutral with regard to jurisdictional claims in published maps and institutional affiliations. 